\title{
COMO FOMOS RECEBIDOS EM FRANÇA
}

Temos a grato prazer de reproduzir e - ao mesmo tempo de agradecer, os amáveis conceitos, para nós verdadeiramente estimulantes, que as revistas francesas, Bulletin Hispanique e Revue Historique publicaram sôbre a nossa Revista de História. Abaixo transcrevemos as referências em apreço.

*

Une nouvelle Revista de História vient de paraître en 1950 à la Faculté des lettres de São Paulo; son comité de rédaction groupe, sous la direction du professeur E. Simóes de Paula, la plupart des historiens de cette Faculté. Elle reprend le titre porté si vaillamment de 1912 à 1928 par la revue du professeur Fidelino de Figueiredo. Prenant como épigraphe la définition de $M$. Lucien Febure "histoire est la science de l'homme", la Revista de História entend ouvrir ses pages à tous les aspects de l'histoire: le sommaire des quatre fascicules'de la première année, où figurent des études d'histoire de la religion grecque, d'étruscologie et d'histoire médiévale à côté d'études d'histoire coloniale, d'histoire du Brésil et $d^{\prime}$ histoire $d u$ positivisme, manifeste combien elle y a réussi. Les noms des maïtres brésiliens, français et anglais qui ont signé ces articles assurent à la Revista de História une place nécessaire dans les bibliothèques de tous les Instituts historiques.

(in Bulletin Hispanique, tome LIII, n.o. 1, 1951, p. 106).

Nous sommes heureux de signaler à l'attention des lecteurs de la Revue Historique la naissance de la nouvelle revue bresilienne, la Revista de História de São Paulo, dont nous avons reçu les six premiers numéros.

Publication trimestrielle dirigée par E. Simões de Paula (in 8.0, 1000 pages par an, environ), ses préoccupations sont axées vers l'histoire totale telle qu'elle a été maintes fois définie par $\mathrm{Lu}$ cien Febvìe. Elle a su grouper autour d'elle une équipe fort cohérente d'historiens brésiliens pleins de dynamisme et de talent, Alice Piffer Cannabrava, Alfredo Ellis Júnior, Livio Teixeira.... il faudrait pouvoir les citer tous; elle compte parmi ses collaborateurs assidus quelques-uns de nos plus grands histoirens et géo- 
graphes: MM. Lucien Febvre, Fernand Braudel, Emile Coornaert; Roger Dion, Émile-G. Léonard, et des savants étrangers d'un renon international: Jaime Cortesão, Damiāo Peres... Elle embrasse tous les secteurs de la science historique, avec une prédilection heureuse pour les problèmes d'histoire brésilienne,. ausquels elle donne toujours leur sens veritable et leur portée universelle.

Line exemple particulièrement heureux, et qu'il fallait signaler, de cet état d'esprit, de ce souci de toujours donner sa vraie por- tée à l'histoire brésilienne et son caractère d'expérience de laboratoire, qui déroule en quelques siècles accessibles à l'histoire des processus qui ont façonné notre vieux monde au cours de millénaires hors de notre portée, est offert par la série d'articles d'Émile-G. Léonard sut le protestantisme brésilien (Brasil, terra de história, 1950, n. ${ }^{\mathbf{2}}$ 2, p. 219-227; O Protestantismo brasileiro. Estudo de eclesiologia e de história social, 1951, n. ${ }^{0} 5, p .105-157, n .^{\circ} 6, p$. 329-379; a suivre...). Dans ces atticles, Émile-G. Léonard développe l'idée lancée par Lucien Febvre en 1929 (Annales d'histoire économique et sociale. Un champ privilégié d'histoire: l'Amérique du Sud, 1929), en l'appliquant à un cas concret: cette curieuse naissance d"un protestantisme brésilien aux XIXe et au début du XXe siècle, qui déroule sous nos yeux quelques-uns des mécanismes qui furent ceux de la Réforme dans notre XVIe siècle européen.

L'effort de la Revista de História de São Paulo doit être suivi de près. Un instrument de prix à inscrire désormais dans nos bibliographies.

(Fierre Chaunu, in Revue Historique, t. CCVII, n. 422 , Avril-Juin 1952, pags. 362-363). 